chromosphere than is at present the case. It is true, that owing to the increased pressure at the surface of the nucleus due to a thicker chromosphere, the temperature there may have been a little higher; but I do not think that difference would make up for the increase in absorption of the chromosphere.

Assuming then that the sun gives out more heat now in a given time than he did during the glacial period, and that the earth had already so far cooled down that her surface was not sensibly more warmed by internal heat than it is in our own epoch, the mean temperature of the earth's climate would have been lower, and the sea-level line of perpetual snow nearer the Equator in both hemispheres; and glaciers would have covered vast tracks of country which are now denuded of them.

Again, let us go back some millions of years in the world's history, till we arrive at the carboniferous period. The sun then would probably be emitting less heat than even during the glacial period; but the earth would not have cooled down to such an extent, and her internal heat would be sensible at the surface. The mean climate of the globe would have probably been warmer then than it is now, and the temperature more equally distributed, depending not so much on solar as on terrestrial radiation. This being supposed, the vegetation of England and India in those days must have presented less difference than what we find at present. Does the flora of our English and Indian coal-beds support or upset this conclusion? Can any of your correspondents answer this query, or set me right if $I \mathrm{am}$ wrong in my hypothesis of solar radiation?

Hampstead, July 22

J. H. RöllRs

P.S.-Is there any good mathematical treatise on heat, English or French, up to the latest information on the subject? Can you or any of your correspondents recommend me such a treatise?

Telescope Tube for Celestial Photography

I HAVE not yet seen any satisfactory plan suggested of getting over the difficulty experienced in celestial photography by the expansion and contraction of telescope tubes, by changes of temperature in metal tubes.

I therefore venture to suggest the following plan, which may be so arranged as to keep the object-glass and camera-slide cxactly the same distance apart, and so keep the true focus when once found. The arrangement would have to be modified according to the metal of which the tube is made, but taking a brass one (the most common), with the camera attached to the eyepiece-slide, the correction will be effected by attaching to the main tube, near the eyepiece, two zinc rods the length of the main tube, upon which they must rest loosely; to the free ends of these, near the object-glass, attach a rod of iron extending to the eye-tube; let this iron rod be attached to the eye-tube when the sensitive-plate is exactly in focus; any change in tem. perature will then have no effect on the focus, for the expansion and contraction of the three metals will keep the distance from object-glass to sensitive-plate constant. All who have worked with a telescope giving sharp definition, will know that this is not an unnecessary precaution, as it may seem to some.

Sydney Observatory, June 14 H. C. Russell

\section{Colour of the Emerald, etc.}

I HAVE to beg "A. H." to refer again to NATURE (July 24) p. 254, col. I, line 23, where he will find it stated that "the emeralds employed were canutillos from Santa Fé de Bogotá. Their specific gravity was 2.69 ." It is evident, therefore, that they could only be the green silicate of alumina and glucina.

The green sapphire, known also as the "oriental emerald," is thie rarest of all gems; and Mr. Harry Emanuel, in his worl, "Diamonds and Precious Stones," speaking of it says, "In the whole course of my experience I have only met with one speci. men." Its specific gravity would at once distinguish it from the true emerald.

The Beryl A. was colourless, opaque, and had a specific gravity of $2 \cdot 65$. GREVILLE IVILLIA.IS

\section{INSTINCT, PERCEPTION, AND REASONING POWER OF ANIMTALS}

THE correctness of the following facts, bearing on the above question, I can warrant :-

A beautiful greybound bitch in my possession had puppies, and I gave one of them, about a month old, to a friend of mine who was also living in Montpellier at that time. Some few days subsequently, on going to call at my friend's house, I took the greyhound with me. She appeared delighted at finding her puppy again, and expressed her strong feeling by lavishing on it, in her own way, the most tender marks of affection. After a few days I paid a second visit to my friend (unaccompanied by the greyhound), when he informed me that, in consequence of the carnest request of one of his friends, he had been induced to give him the puppy, which had thus been removed to a considerable distance. I returned home, and on my arrival was struck with the peculiar manner in which the animal met me. There was nothing of her usual expression of delight-no barking no jumping to and fro-but she met me with a serious and thoughtful look, and began slowly to smell my clothes in different places, with the most earnest perseverance. Nor was she content with a mere cursory effort to discover the particular object, whatever it was, which, no doubt, she had in view; but she continued the same course of proceeding for at least a quarter of an hour, in fact, till I found it quite necessary to bring it to a close.

From the above statement of the conduct of the animal, the impression on my own mind was that I must have carried away from my friend's house some subtle effluvia, which tended to bring back to the mother the recollection of her puppy. And this caused me some additional sur. prise, inasmuch as greyhounds are possessed of great keenness of sight, but are gencrally considered as rather deficient in their power of smelling. The conclusion is still more remarkable. During the space of about two years I usually paid my friend a visit twice a week, and on every occasion, on my return home, the greyhound would invariably go through the same ceremony. At length the proceeding became altogether so striking that it was quite unnecessary for my wife and family (perhaps from a little innocent curiosity) to ask, "Where have you been?" They could save themselves the trouble of a question and say "I see that you have been calling on your friend."

My cousins were residing in a small village about thirty kilom. from Montpellier, and on one occasion, when I was going to spend some days with them, I took, for the first time, my greyhound with me. It so happened that not far off there was a hound bitch that belonged to one of my cousins' neighbours, and between these two animals (from the beginning of my short stay) there arose the deepest hatred and animosity, and conflicts of the most ferocious kind were matters of daily, alnost hourly, occurrence. Time altogether failed in producing any better feeling between them, and to the end of my visit each was ever ready and anxious to try their strength whenever the opportunity offered. In the course of the following year I paid a second visit to the same place, accompanied by my greyhound, and about three-quarters of an hour before I reached the village the animal, as if struck with a sudden idea, rushed forward at her full speed, and all attempts to call her back proved quite ineffectual, On reaching the village I found that a terrible encounter had already taken place between the two heroines, who were on the point of renewing the attack after a temporary cessation of hos. tilities,

The following anecdote relating to the same greyhound seems to prove that these animals may sometimes exhibit a higher standard of reasoning power than according to general opinion they possess.

I was passing some days in the country with my aunt, who had a middle-sized spaniel bitch, of a somewhat sullen and treacherous temper. This spaniel observed, with an evident feeling of jealousy, that my greyhound was making herself quite at home in my aunt's kitchen, and whenever she had a favourable opportunity, without 